\title{
Measurement of blood pressure in children
}

\author{
Recommendations of a working party of the British Hypertension Society
}

M de Swiet, M J Dillon, W Littler, E O’Brien, P L Padfield, J C Petrie

This report follows the previous recommendations of the British Hypertension Society on blood pressure measurements in adults ${ }^{1}$ and considers the techniques for measuring blood pressure in children and the circumstances in which blood pressure might be measured.

\section{Measurement techniques}

The only technique that is practicable for widespread clinical application is conventional sphygmomanometry with a well maintained mercury sphygmomanometer. Measurement of systolic blood pressure is preferred to diastolic blood pressure because of its greater accuracy and consistency. The choice of the correct cuff is crucial. To cover the age range 0 - 14 years a minimum of three cuffs is necessary; recommended bladder sizes are $4 \times 13 \mathrm{~cm}, 8 \times 18 \mathrm{~cm}$, and $12 \times 35 \mathrm{~cm}$ (adult cuff). The widest cuff that can be applied to the arm should be used. The length of the inflation bladder should be at least two thirds of the circumference of the arm and preferably longer. Secure fastening is essential; this may not be possible with Velcro, especially when using the smaller cuffs.

In some healthy children aged under 5 years and all children aged under 1 year measurement of blood pressure by conventional sphygmomanometry is impossible because the Korotkoff sounds cannot be heard reliably. In these children and children who are in shock or who have low cardiac outputs more sensitive detection systems such as Doppler ultrasound or oscillometry should be used.

J C Petrie, FRCPED, professor of clinical pharmacology

Correspondence to:

Dr de Swiet.

BrMed f 1989:299:497

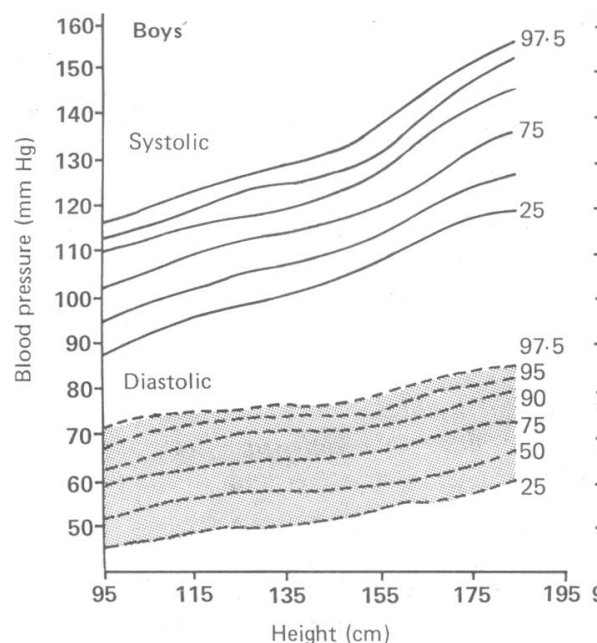

Circumstances of measurement

Except in acutely ill children blood pressure should be measured after the child has been sitting quietly (or

Relation of blood pressure to height in children. Figures are percentages of boys and girls. Data redrawn with permission from André et al lying if aged under 2 years) for at least three minutes. Measurements made when the child is eating, sucking, or crying will be unrepresentative and usually too high. Decisions about the child's management should not be taken on the basis of measurements of blood pressure taken on a single occasion.

\section{Normal values}

At the age of 4 days the median systolic blood pressure is $75 \mathrm{~mm} \mathrm{Hg}$ (95th centile $95 \mathrm{~mm} \mathrm{Hg}$ ) and at 2 years the median is $95 \mathrm{~mm} \mathrm{Hg}(115 \mathrm{~mm} \mathrm{Hg})$. Between the ages of 2 and 14 years blood pressure changes little; body size (represented by body length) is a better criterion by which to judge the normality of blood pressure measurements. The figure shows the relation of blood pressure to body length. More complex functions of height and weight have been used to adjust blood pressure, but for clinical purposes height alone is adequate and simple to use. The increase in height at puberty compensates for the increase in blood pressure occurring at that age. After the age of 14 the criteria applied to adults should be used for assessing blood pressure.

\section{Indications for measurement}

Sick children should have their blood pressure measured whenever a general medical examination is indicated.

The following groups of children should have regular blood pressure measurements: $(a)$ those who have been found to have high blood pressure on a previous occasion, $(b)$ those with any disease of the kidneys, ureters, or bladder, and $(c)$ those with diabetes.

Screening for blood pressure is probably not justified. Blood pressure in children is very variable. Measurements of blood pressure in the community have suggested that at most only $1 \%$ of children have blood pressures consistently and appreciably greater than the 95th centile for single measurements. Children with a family history of hypertension, however, may be at greater risk. By extrapolation from results in adult hypertension, children with severe primary hypertension and with secondary hypertension are likely to benefit from investigation and treatment, but the cost-benefit ratio from identifying these by screening is not clear. At present, population screening to identify children with "hypertension" is not recommended.

1 Petrie JC, O'Brien E'T, Littler WAW, de Swiet M. Recommendations on blood pressure measurement. British Hypertension Society. Br Med $\mathcal{F}$ 1986;293 $611-5$

2 André JL, Deschamps JP, Gueguen R. La tension atérielle chez l'enfant et l'adolescent. Valeurs rapportées à l'âge et à la taille chez 17067 sujets. Arch Fr Pediatr 1980;37:477-82. 